\title{
Expression pattern of HMGB1 and its association with autophagy in acute necrotizing pancreatitis
}

\author{
CAN YU ${ }^{1}$, XIAO YU ${ }^{1}$, HONG-WEI ZHU ${ }^{1}$, XIA LI $^{2}$, LI-HUA HUANG $^{3}$, \\ ZHI-QIANG LI ${ }^{1}$, DUO HAN ${ }^{1}$ and HUI HUANG ${ }^{1}$ \\ Departments of ${ }^{1}$ Hepatobiliary and Pancreatic Surgery, and ${ }^{2}$ Endocrinology; ${ }^{3}$ Center for Medical Experiments, \\ Third Xiangya Hospital, Central South University, Changsha, Hunan 410013, P.R. China
}

Received July 31, 2015; Accepted July 27, 2016

DOI: $10.3892 / \mathrm{mmr} .2016 .5945$

\begin{abstract}
High-motility group box protein 1 (HMGB1) has an important role in autophagy; however, its exact role in acute necrotizing pancreatitis (ANP) remains unknown. The present study aimed to investigate the expression pattern of HMGB1 in ANP, and to determine its association with autophagy. Sprague Dawley rats (weight, 350 $\pm 30 \mathrm{~g}, \mathrm{n}=48$ ) were randomly divided into control $(n=12)$ and experimental $(n=36)$ groups. Experimental rats were retrogradely injected with 5\% sodium taurocholate into the biliopancreatic duct to induce ANP. Control rats received an equal amount of saline. Serum amylase levels were used to determine whether the model had been successfully generated. Autophagosomes in pancreatic acinar cells were observed under electron microscopy. The expression levels of HMGB1 and Beclin 1 were detected in pancreatic tissues by western blotting, quantitative polymerase chain reaction and immunohistochemistry. HMGB1 levels were also determined in the serum and in isolated nuclei. The results demonstrated that autophagy was detected at $3 \mathrm{~h}$ post-ANP induction; however, HMGB1 expression remained unaltered during the early stage $(0-6 \mathrm{~h} ; \mathrm{P}>0.05)$. HMGB1 expression was significantly increased at $12 \mathrm{~h}$, and was still increasing at $24 \mathrm{~h}(\mathrm{P}<0.05)$. Notably, HMGB1 was increased in the nuclei compared with in the cytoplasm at 3-6 h. Furthermore, serum HMGB1 levels began to increase at $3 \mathrm{~h}$, and reached the highest levels at $24 \mathrm{~h}$ in the ANP group. In conclusion, in an ANP model, HMGB1 was initially increased in the nuclei to initiate autophagy. Subsequently, it moved into the cytoplasm, where it interacted with Beclin 1 to enhance autophagy, and HMGB1 was released into the blood, leading to the deterioration of ANP.
\end{abstract}

Correspondence to: Dr Xiao Yu, Department of Hepatobiliary and Pancreatic Surgery, Third Xiangya Hospital, Central South University, 138 Tongzipo Road, Changsha, Hunan 410013, P.R. China E-mail: yuxiaoyx4@126.com

Key words: acute necrotizing pancreatitis, autophagy, inflammation, Beclin 1, HMGB1

\section{Introduction}

Acute pancreatitis (AP) is an acute, reversible inflammatory disease of the pancreas, which may affect several organs (1). Necrotizing pancreatitis is characterized by the presence of necrosis in pancreatic and/or peripancreatic tissues (2). The incidence of AP varies from 17.5 to 109 per 100,000 admissions to emergency departments $(3,4)$. The risk factors for AP remain unknown; however, smoking, gallstones, alcohol and drugs are likely to increase the risk of AP and chronic pancreatitis (5). AP leads to local and systemic complications, with an overall mortality rate of $4 \%$. In addition, the mortality rate for acute necrotizing pancreatitis (ANP) is $10-25 \%(1,6)$. Ultrastructural alterations to the pancreatic tissues of patients with ANP were observed $>30$ years ago, including morphological changes in zymogen granules and increased autophagy in the pancreatic acinar cells (7). Watanabe et al (8) described the morphological features of autophagy in cerulein-induced $\mathrm{AP}$, leading to the understanding of the association between autophagy and AP. In the pathogenesis of pancreatitis, intracellular trypsinogen activation has an important role in its development (9). Morphological changes in zymogen granules and activation of plasminogen are associated with the formation of cytoplasmic vacuoles, which have an important role in autophagy (10).

In cell nuclei, high-motility group box protein 1 (HMGB1) has a role in the transcription of numerous genes, which are crucial to the autophagy process (11-14). In the cytoplasm, HMBG1 binds to Beclin 1, thus sustaining the Beclin 1-Ptdlns3KC3 complex during the activation of autophagy (15). Extracellular HMGB1 is involved in the inflammatory response of ANP by triggering secretion of cytokines, including tumor necrosis factor (TNF)- $\alpha$ and interleukin (IL)-1 $\beta$ (16,17). Furthermore, as a late inflammatory factor, HMGB1 has been reported to have a key role in the development of AP (18).

The exact expression pattern of HMGB1 during ANP development remains unknown. Therefore, the present study aimed to investigate the involvement of HMGB1 in the development of ANP, in order to explore the role of HMGB1 and the autophagy signal Beclin 1 in the development of ANP. The results of the present study may provide evidence regarding the treatment of ANP. 


\section{Materials and methods}

Materials and reagents. A total of 48 healthy male Sprague Dawley rats (weight, $350 \pm 30 \mathrm{~g}$; age, 12-14 weeks), were provided by the Experimental Animal Center of the Third Xiangya Hospital (Changsha, China). Sodium taurocholate was purchased from Sigma-Aldrich (Merck Millipore, Darmstadt, Germany). Amylase polyclonal antibody (cat. no. YT5164) and enzyme-linked immunosorbent assay (ELISA) kit for HMGB1 (Total HMG-1 Cell-Based Colorimetric ELISA kit) were obtained from ImmunoWay Biotechnology Company (Plano, TX, USA). Rabbit anti-HMGB1 (cat. no. ab79823) and anti-Beclin 1 (cat. no. ab55878) primary antibodies were from Abcam (Cambridge, MA, USA). Goat anti-rabbit secondary antibodies were purchased from Jackson ImmunoResearch (West Grove, PA, USA; cat. no. 111-005-144). The color pre-stained protein marker was purchased from Fermentas (Thermo Fisher Scientific, Inc., Waltham, MA, USA). The Bradford protein concentration assay kit was obtained from Beyotime Institute of Biotechnology (Haimen, China). TRIzol ${ }^{\circledR}$ reagent was purchased from Invitrogen (Thermo Fisher Scientific, Inc.). The SYBR Green quantitative polymerase chain reaction (qPCR) Mix was purchased from Toyobo Co., Ltd. (Osaka, Japan).

Establishment of animal models and experimental groups. The present study was approved by the ethics committee of the Experimental Animal Center of the Third Xiangya Hospital. The rats were housed at a constant temperature of $22^{\circ} \mathrm{C}$ under a 12-h light/dark cycle. The rats had access to standard food and water ad libitum. The ANP rat model was created according to the method described by Aho et al (19). The rats were fasted for $24 \mathrm{~h}$, with ad libitum access to water. Subsequently, the rats were anesthetized by intraperitoneal injection with $10 \%$ chloral hydrate $(0.3 \mathrm{ml} / 100 \mathrm{~g})$. An incision was made into the ventral midline for entry into the abdominal cavity, in order to expose the common bile duct and the pancreatic duct. The biliopancreatic duct was occluded at the distal duodenum using a vascular clip. For the experimental group, the canal was infused slowly with $5 \%$ sodium taurocholate $(0.1 \mathrm{ml} / 100 \mathrm{~g})$ using a 1-ml syringe at the proximal end. For the control group, the canal was infused with an equal quantity of normal saline. After injection, the needle remained motionless for $10 \mathrm{~min}$ to prevent drug reflux. After modeling, the skin was disinfected, the peritoneum was closed with a continuous single-layer suture, and the skin was sutured with a full-layer simple-interval suture. After the abdomen had been closed, the rats were injected with $5 \mathrm{ml}$ saline at the inside position of the lower limb muscle to supplement water lost during the operation.

Experimental (ANP) rats were grouped according to the following time points after modeling: $0 \mathrm{~h}(\mathrm{n}=4), 3 \mathrm{~h}(\mathrm{n}=8)$, $6 \mathrm{~h}(\mathrm{n}=8), 12 \mathrm{~h}(\mathrm{n}=8)$ and $24 \mathrm{~h}(\mathrm{n}=8)$. The control rats were grouped according to the following time points: $3 \mathrm{~h}(\mathrm{n}=3), 6 \mathrm{~h}$ $(\mathrm{n}=3), 12 \mathrm{~h}(\mathrm{n}=3)$ and $24 \mathrm{~h}(\mathrm{n}=3)$. Rats were sacrificed, at the aforementioned time points, by cardiac puncture following anesthetization by intraperiotneal injection with $10 \%$ chloral hydrate $(0.3 \mathrm{ml} / 100 \mathrm{~g}$ body weight).

Specimen collection and preservation. Rats were anesthetized and sacrificed. Blood samples $(\sim 5 \mathrm{ml})$ were collected from the heart, which were maintained at $4^{\circ} \mathrm{C}$ for $30 \mathrm{~min}$ and centrifuged at $1,000 \mathrm{x} g$ for $15 \mathrm{~min}$ at normal temperature. The supernatant was then collected and preserved at $-80^{\circ} \mathrm{C}$, avoiding repeated freezing and thawing. For electron microscopy, pancreatic specimens were maintained in $4 \%$ paraformaldehyde for $24 \mathrm{~h}$ at $4{ }^{\circ} \mathrm{C}$, and were then transferred to tissue preservation solution ( $0.2 \%$ sodium azide) for preservation. Other pancreatic tissues were collected, placed in cryogenic tubes and maintained in liquid nitrogen.

Detection of serum amylase and HMGBI levels by ELISA assay. Serum amylase and HMGB1 levels were used to determine if ANP modeling was successful. Serum amylase and HMGB1 levels were assessed using ELISA, according to the manufacturer's protocol with the amylase antibody used at a dilution of 1:20,000.

Electron microscopy. The pancreatic tissues were trimmed to $1 \times 1 \times 1 \mathrm{~mm}^{3}$, fixed with $2.5 \%$ pentanediol for $24 \mathrm{~h}$, and post-fixed with $2 \%$ osmium tetroxide for $2 \mathrm{~h}$; dehydrated with a gradient of $50 \%, 70 \%, 90 \%$, and $100 \%$ dehydrated acetone, in each solution three times with each time $10 \mathrm{~min}$. The samples were then placed in an epoxy resin and pure acetone mixture (1:1) at $37^{\circ} \mathrm{C}$ for $24 \mathrm{~h}$, prior to embedding in a mixture of Epon 812 resin, methyl nadic anhydride, dodecenylsuccinic anhydride, and dimethylaminomethyt phenol, at $60^{\circ} \mathrm{C}$ for $24 \mathrm{~h}$. The blocks were trimmed with semi-thin glasscutter, stained with toluidine blue, and observed under light microscopy to select areas with pancreatic acinar structure. Ultrathin sections with a thickness of $500 \AA$ were obtained with an ultrathin microtome and stained with uranyl acetate and lead nitrate. The sections were observed under transmission electron microscopy (Nissan HT7700; Nissan Corporation, Tokyo, Japan) to examine changes of the pancreatic acinar autophagosomes.

Immunohistochemistry of HMGB1 and Beclin 1 in pancreatic tissue. Sections $(4 \mu \mathrm{m})$ of paraffin-embedded pancreatic tissues were dewaxed and hydrated, and were washed three times with phosphate-buffered saline (PBS; pH 7.4; 5 min/wash). Subsequently, the samples were boiled under high-pressure in $10 \mathrm{mM}$ citric acid buffer ( $\mathrm{pH}$ 6.0) for $30 \mathrm{~min}$ for antigen retrieval, cooled to room temperature, and washed with distilled water and PBS (2x5 min). Sections were incubated with 3\% hydrogen peroxide at room temperature for $1 \mathrm{~min}$, and were washed three times with PBS (5 min/wash). Sections were then blocked with goat antiserum (Abcam) for $7 \mathrm{~min}$ at $37^{\circ} \mathrm{C}$, and were washed with PBS (5 min). Subsequently, the samples were incubated with the following primary antibodies at $4^{\circ} \mathrm{C}$ overnight: Anti-HMGB1 or anti-Beclin 1 (1:200). Sections were then rinsed three times with PBS (5 min/wash), and a biotinylated secondary antibody (1:100) was then added to the sections, which were incubated at room temperature for $1 \mathrm{~h}$ and rinsed in a humidified chamber. Subsequently, enzyme-labeled streptavidin (50 $\mu \mathrm{l}$; Wuhan Boster Biological Technology, Co., Ltd., Wuhan, China) was added, incubated at room temperature for $30 \mathrm{~min}$ and rinsed in a humidified chamber. Sections were stained with DAB (Sigma-Aldrich; Merck Millipore), observed under a BX53 microscope (Olympus Corporation, Tokyo, Japan), and when the color was suitable, the staining reaction was terminated by rinsing. Sections were then counterstained with hematoxylin, rinsed with water, dehydrated in 
Table I. Serum amylase levels in a rat ANP model, as determined by enzyme-linked immunosorbent assay.

\begin{tabular}{lccrr}
\hline Group & $3 \mathrm{~h}$ & $6 \mathrm{~h}$ & $12 \mathrm{~h}$ & $24 \mathrm{~h}$ \\
\hline Control & $62.81 \pm 8.05$ & $65.81 \pm 6.31$ & $70.81 \pm 8.57$ & $78.81 \pm 6.46$ \\
ANP & $734.13 \pm 65.30^{\mathrm{a}}$ & $1206.76 \pm 83.27^{\mathrm{a}, \mathrm{b}}$ & $2006.24 \pm 119.81^{\mathrm{a}, \mathrm{b}}$ & $1825.90 \pm 105.14^{\mathrm{a}, \mathrm{b}}$ \\
\hline
\end{tabular}

Units (determined by relative pixel intensity), $\mathrm{pg} / \mathrm{ml}$. Results are presented as the mean \pm standard deviation. ${ }^{\text {a }}<<0.05 \mathrm{vs}$. the control group; ${ }^{b} \mathrm{P}<0.05$ vs. the preceding time point. ANP, acute necrotizing pancreatitis.

gradient alcohol, cleared with xylene, and finally sealed with neutral resin. Images were captured using a camera system (Motic B5; Motic, Xiamen, China). Yellow-brown staining of the nuclei or cytoplasm was recognized as positive staining. Densitometric quantitative analysis of the expression levels was carried out using the Image-Pro Plus 6.0 image system (Media Cybernetics, Inc., Rockville, MD, USA).

Nuclear extraction. Tissue samples were washed with saline to remove blood. Subsequently, $400 \mu$ l solution A [200 $\mu 1 \mathrm{KCl}$ (10 mM), 2 ml HEPES (10 mM, pH 7.9), $20 \mu$ I EDTA (0.1 mM), $1.2 \mathrm{ml} \mathrm{MgCl}$ (1.5 mM), $200 \mu \mathrm{l}$ DTT (1 mM), $100 \mu \mathrm{l}$ PMSF $(0.5 \mathrm{mM})$ and $16.28 \mathrm{ml}$ of $\mathrm{dH}_{2} \mathrm{O}$ ] was added. Tissue samples were homogenized and placed on ice for $15 \mathrm{~min}$. Samples were then centrifuged at $15,000 \times \mathrm{g}$ for $1 \mathrm{~min}$ at $4^{\circ} \mathrm{C}$. The supernatants (cytoplasmic proteins) were transferred to a new tube, and the pellet (nuclei) was resuspended in $400 \mu 1$ solution B [5 ml glycerol (25\%), 4 ml HEPES (20 mM; pH 7.9), 4 ml NaCl (400 mM), $200 \mu 1$ EDTA ( $1 \mathrm{mM}), 200 \mu \mathrm{l}$ DTT (1 mM), $200 \mu \mathrm{l}$

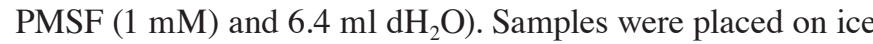
for $20 \mathrm{~min}$, and were then centrifuged at 15,000 $\mathrm{x} g$ for $10 \mathrm{~min}$ at $4^{\circ} \mathrm{C}$. The supernatants (nuclear proteins) were transferred to new tubes and were stored at $-80^{\circ} \mathrm{C}$ until further use.

Western blot analysis for HMGB1 and Beclin 1. Following extraction of the cytoplasmic and nuclear proteins, 5\% SDS-polyacrylamide gel electrophoresis was used to separate the proteins (10 $\mu \mathrm{g}$ samples), which were then transferred to polyvinylidene fluoride (PVDF) membranes. After blocking with $5 \%$ skim milk at room temperature for $2 \mathrm{~h}$, the PVDF membranes were agitated overnight at $4^{\circ} \mathrm{C}$ with anti-HMGB1 or anti-Beclin $1(1: 1,000)$. Subsequently, the membranes were agitated with horseradish peroxidase-labeled goat anti-rabbit secondary antibody $(1: 1,000)$ at room temperature for $1 \mathrm{~h}$. The blots were visualized following treatment with enhanced chemiluminescence solution in a dark room for light exposure. The PVDF membrane was then cleaned with eluent to remove antibodies, and was hybridized with rabbit polyclonal anti- $\beta$-actin antibodies (1:1,000; Abcam; cat. no. ab8227) or rabbit anti-histone H3 (1:1,000; RayBiotech, Inc., Norcross, GA, USA; cat. no. 168-10463) and a goat anti-rabbit horseradish-peroxidase secondary antibody (1:1,000; Abcam; cat. no. ab6721). The films were scanned, the optical density values of HMGB1, Beclin 1 and $\beta$-actin (internal control) bands were measured using an image analysis system (Quantity One software version 4.62; Bio-Rad Laboratories, Inc., Hercules, CA, USA), and the ratios were obtained for semi-quantitative analysis.
qPCR for HMGB1 and Beclin 1. Total RNA was extracted from the pancreatic tissues using TRIzol ${ }^{\circledR}$ at various time points $(0,3,6,12$ and $24 \mathrm{~h})$ following ANP modeling. For each sample, $2.0 \mu \mathrm{g}$ total RNA was reverse transcribed to cDNA using $1 \mu \mathrm{l}$ oligo (dT) $(0.5 \mu \mathrm{g} / \mu \mathrm{l})$ primer according to the protocol of the First Strand cDNA Synthesis kit (Thermo Fisher Scientific, Inc.). PCR primers were designed according to the gene sequences downloaded from National Center for Biotechnology Information (http://www.ncbi.nlm.nih. gov/genbank/) using Primer 5.0 software (Premier Biosoft, Palo Alto, CA, USA). The PCR primer sequences were sequenced by Sangon Biotech., Co., Ltd. (Shanghai, China) as follows: HMGB1, sense 5'-GCTCAGAGAGGTGGAAGAC-3', antisense 5'-CCAATGGATAAGCCAGGAT-3'; Beclin 1, sense 5'-TGTGGAATGGAATGAAATCAA-3', antisense 5'-CCCCCAGAACAGTACAACGGC-3'; and $\beta$-actin (internal reference), sense 5'-CCCATCTATGAGGGTTACGC-3' and antisense 5'-TTTAATGTCACGCACGATTTC-3'. The PCR cycling conditions were as follows: Pre-denaturation at $95^{\circ} \mathrm{C}$ for $3 \mathrm{~min}$; denaturation at $95^{\circ} \mathrm{C}$ for $10 \mathrm{sec}$, and annealing and extension at $58^{\circ} \mathrm{C}$ (HMGB1 and $\beta$-actin) or $60^{\circ} \mathrm{C}$ (Beclin 1) for $30 \mathrm{sec}$, for a total of 35 cycles. The PCR reaction was performed in a total of $20 \mathrm{ml}$, including $10 \mu \mathrm{l} 2 \mathrm{X}$ SYBR Green qPCR mix, $1 \mu \mathrm{l}$ primers $(10 \mu \mathrm{M}), 1 \mu \mathrm{l} \mathrm{cDNA}$ and $8 \mu \mathrm{l}$ DEPC-water, the reaction was conducted in an Eppendorf MasterCycler Realplex qPCR machine. Fluorescence was read at each extension phase. The $\mathrm{Cq}$ values were obtained and calculated by $2^{-\Delta \Delta \mathrm{Cq}}$ formula (20) relative to the mean of $0 \mathrm{~h}$ values, to get the relative expression values.

Statistical analysis. Data are presented as the mean \pm standard deviation, and were analyzed using Student's t-test and one-way analysis of variance followed by the Student-Newman-Keuls post-hoc test. SPSS 13.0 (SPSS Inc., Chicago, IL, USA) was used for statistical analysis. $\mathrm{P}<0.05$ was considered to indicate a statistically significant difference.

\section{Results}

Successful model generation. As presented in Table I, amylase levels were increased $3 \mathrm{~h}$ after modeling. No rats succumbed within the $24 \mathrm{~h}$ experimental period. This is consistent with our previous modeling approach (21).

TEM. As presented in Fig. 1, phagocytic vesicles appeared in some pancreatic cells at $3 \mathrm{~h}$. The number of phagocytic vesicles increased in a time-dependent manner. These vesicles exhibited typical autophagy-like morphology (Fig. 1A-E). 

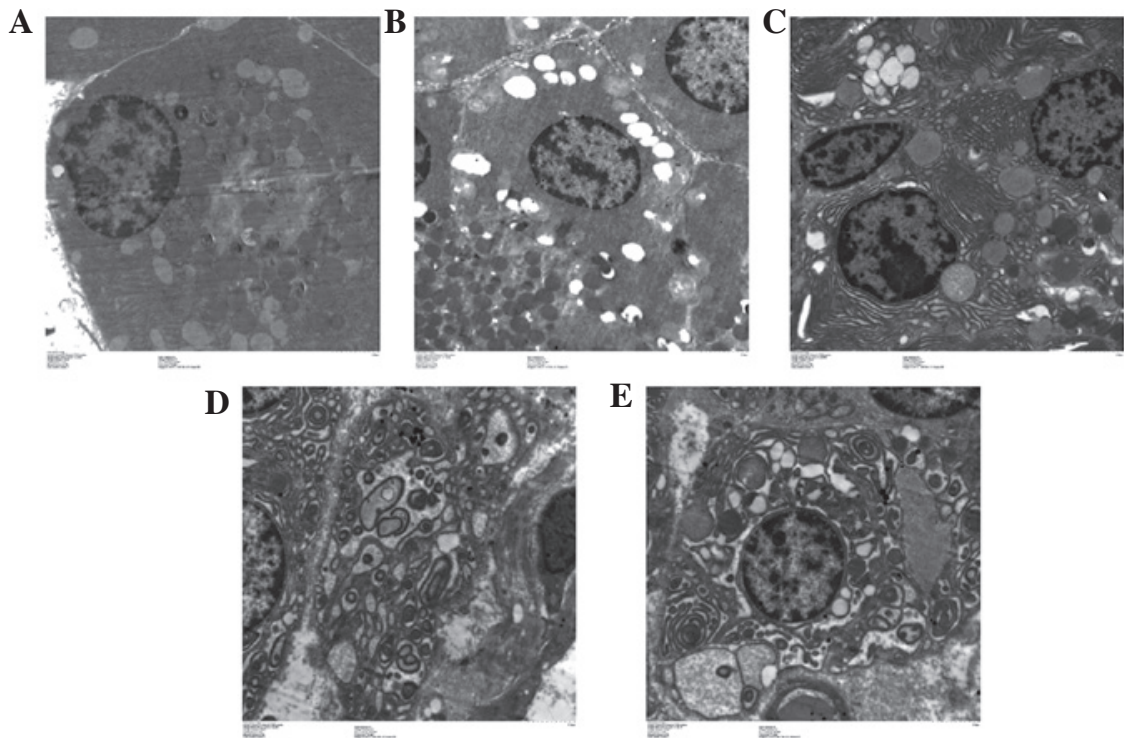

Figure 1. Autophagy observed under transmission electron microscopy. (A) Pancreatic acinar cells in the acute necrotizing pancreatitis (ANP)-0 h group exhibited normal acinar nucleolus, mitochondria and rough endoplasmic reticulum. Occasionally, visible phagosomes and lysosomes were generated due to the normal stress of starvation. (B) In the ANP-3 h group, the number of phagocytic vesicles was increased, indicating enhanced autophagy. (C) In the ANP-6 h group, the pancreatic acinar cells exhibited cystic expansion of the endoplasmic reticulum, mitochondrial swelling, and margination of nuclear chromatin (D) In the ANP-12 h group, phagosomes continued to increase, and the fusion of phagocytic vesicles with lysosomes increased, resulting in a large number of double membrane-like structures. (E) In the ANP-24 h group, the large number of double membrane-like structures increased, providing membrane sources for phagosome formation. Magnification, x10,000.

A

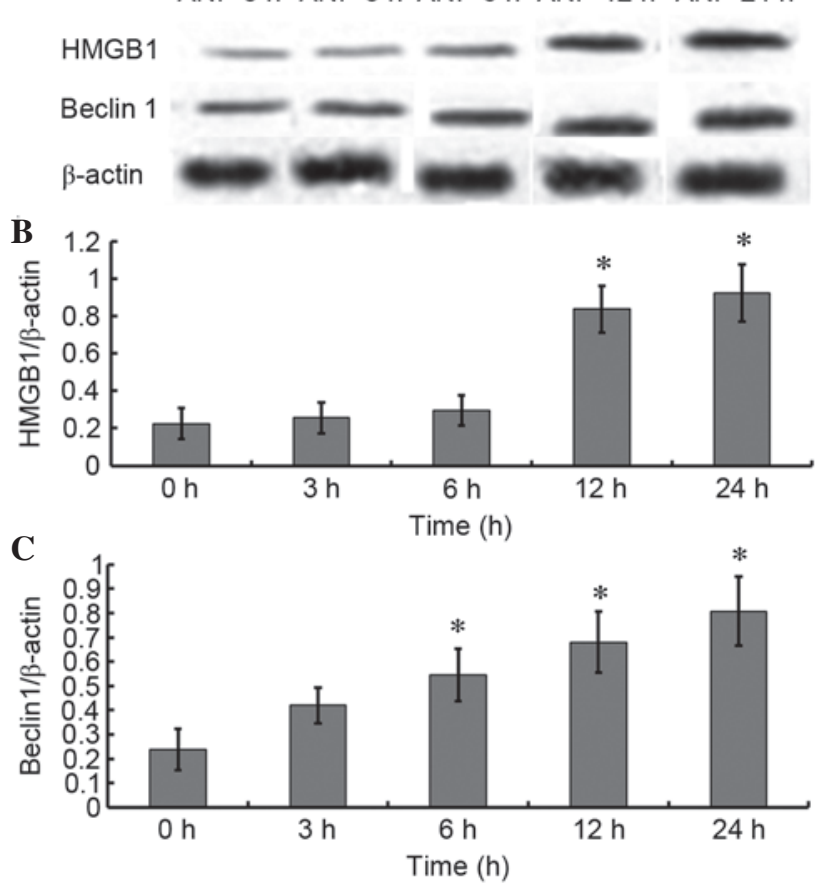

Figure 2. (A) Protein expression, as detected by western blotting. (B) Comparison of high-motility group box protein 1 (HMGB1) expression among the acute necrotizing pancreatitis (ANP)-0, ANP-3 and ANP-6 $\mathrm{h}$ groups exhibited no significant difference ("P $>0.05)$. HMGB1 expression in the ANP-12 $\mathrm{h}$ group was significantly increased, and was maintained at high levels at $24 \mathrm{~h}\left({ }^{*} \mathrm{P}<0.05\right)$. (C) Beclin 1 protein expression in pancreatic tissues of the ANP group. Expression at each time point was significantly increased compared with the preceding time point $\left({ }^{*} \mathrm{P}<0.05\right)$.

HMGB1 and Beclin 1 expression in pancreatic tissue. The protein expression levels of HMGB1 and Beclin 1 were detected

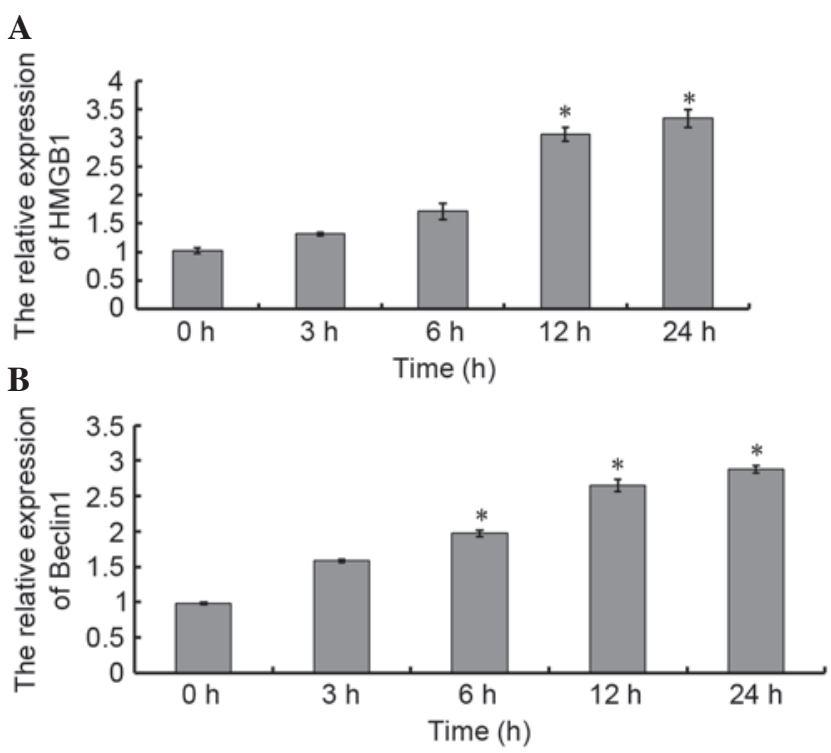

Figure 3. High-motility group box protein 1 (HMGB1) and Beclin 1 mRNA expression in pancreatic tissues of the acute necrotizing pancreatitis (ANP) group at various time points, as determined by quantitative polymerase chain reaction. (A) Comparison of HMGB1 between the ANP-0, ANP-3 and ANP-6 $\mathrm{h}$ groups exhibited no significant difference ( $\mathrm{P}>0.05)$. HMGB1 expression in the ANP-12 h group was significantly increased, and was maintained at high levels at $24 \mathrm{~h}\left({ }^{*} \mathrm{P}<0.05\right)$. (B) Beclin 1 mRNA expression in the pancreatic tissues of the ANP group. Expression at each time point was significantly increased compared with the preceding time point (" $\mathrm{P}<0.05)$.

by western blotting (Fig. 2). As presented in Fig. 2A and B, the protein expression levels of HMGB1 began to increase at $12 \mathrm{~h}$; this finding was supported by the results of a qPCR (Fig. 3A). However, unlike HMGB1, the translation (Fig. 2A and C) and transcription levels (Fig. 3B) of Beclin 1 began to increase 
Table II. Quantitative analysis of Beclin 1 and HMGB1 immunohistochemistry in a rat model of acute necrotizing pancreatitis.

\begin{tabular}{|c|c|c|c|c|c|}
\hline Protein & $0 \mathrm{~h}$ & $3 \mathrm{~h}$ & $6 \mathrm{~h}$ & $12 \mathrm{~h}$ & $24 \mathrm{~h}$ \\
\hline Beclin 1 & $1.72 \pm 0.16$ & $4.72 \pm 0.62^{\mathrm{a}}$ & $8.86 \pm 0.59^{\mathrm{a}}$ & $14.66 \pm 0.61^{\mathrm{a}}$ & $19.52 \pm 0.77^{\mathrm{a}}$ \\
\hline HMGB1 & $3.72 \pm 0.86$ & $3.76 \pm 0.82$ & $4.86 \pm 0.99$ & $12.46 \pm 0.88^{\mathrm{a}}$ & $18.50 \pm 0.87^{\mathrm{a}}$ \\
\hline
\end{tabular}

Data are presented as the mean \pm standard deviation. ${ }^{a} \mathrm{P}<0.05$ vs. the preceding time point. HMGB1, high-motility group box protein 1 .

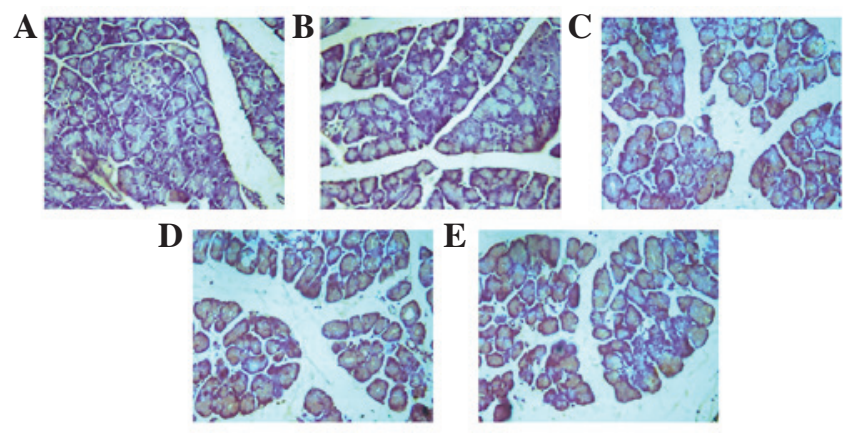

Figure 4. Immunohistochemical analysis of Beclin 1 expression in pancreatitis tissues. (A) Acute necrotizing pancreatitis (ANP)- 0 h group. (B) ANP-3 h group. (C) ANP-6 h group. (D) ANP-12 h group. (E) ANP-24 h group. Magnification, $\mathrm{x} 400$.

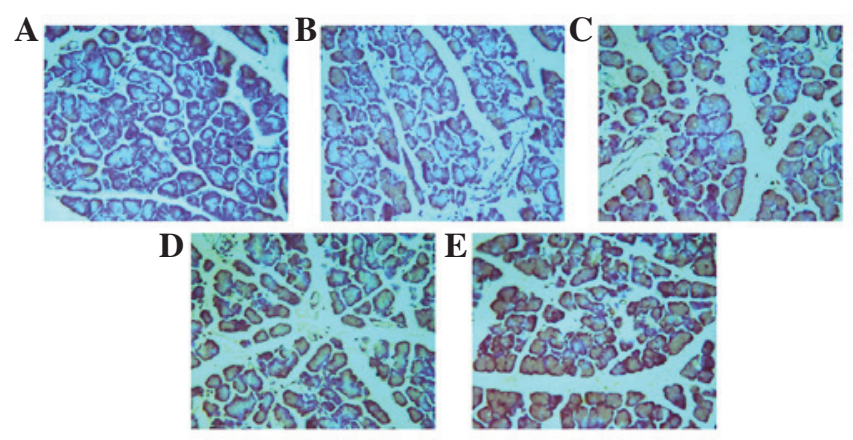

Figure 5. Immunohistochemical analysis of high-motility group box protein 1 (HMGB1) expression in pancreatitis tissues. (A) Acute necrotizing pancreatitis (ANP)- $0 \mathrm{~h}$ group. (B) ANP-3 h group. (C) ANP-6 h group. (D) ANP-12 h group. (E) ANP-24 h group. Magnification, $\mathrm{x} 400$.

at 3 h. Similar expression patterns of HMGB1 and Beclin 1 were observed using immunohistochemistry (Figs. 4 and 5, Table II).

Nuclear protein levels of HMGB1 in pancreatic cells in the early stage of ANP. Based on the TEM results, autophagy appeared at $3 \mathrm{~h}$, which corresponded with the increase in amylase levels at $3 \mathrm{~h}$. However, HMGB1 levels did not increase until $12 \mathrm{~h}$. Since HMGB1 is a nuclear factor, it may promote autophagy from the nucleus (22). Therefore, the nuclei were isolated in the present study. Notably, HMGB1 was shown to be accumulated in the nuclei at the early stage of ANP (Fig. 6).

HMGB1 may be secreted and induce systemic lesions as an inflammatory factor. It has previously been reported that HMGB1 may be secreted outside of cells, where is has a role as an inflammatory cytokine (23). ELISA was used to evaluate
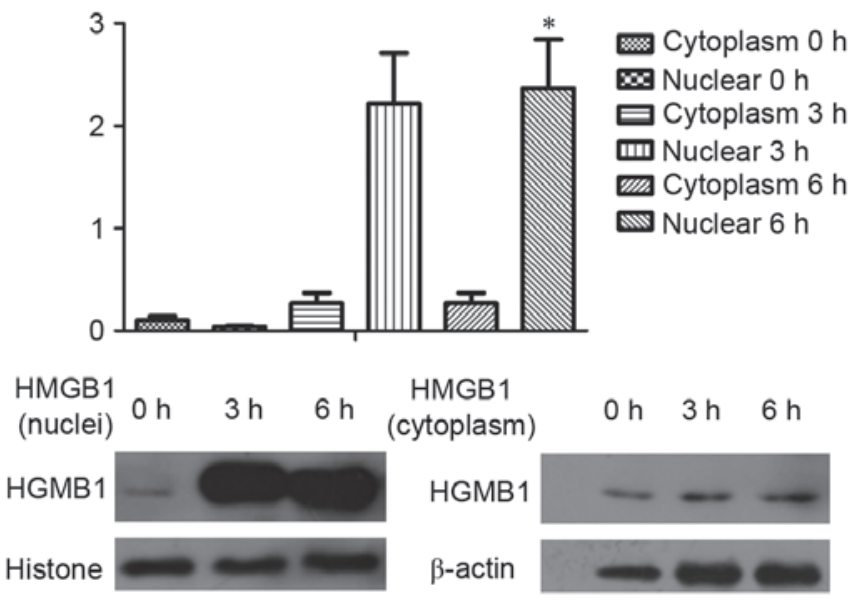

Figure 6. Expression of high-motility group box protein 1 (HMGB1) in the cytoplasm and nuclei of pancreatitis tissues at 0,3 and $6 \mathrm{~h}$ after induction of acute necrotizing pancreatitis. ${ }^{*} \mathrm{P}<0.05$ vs. HMGB1 at 3 and $6 \mathrm{~h}$.

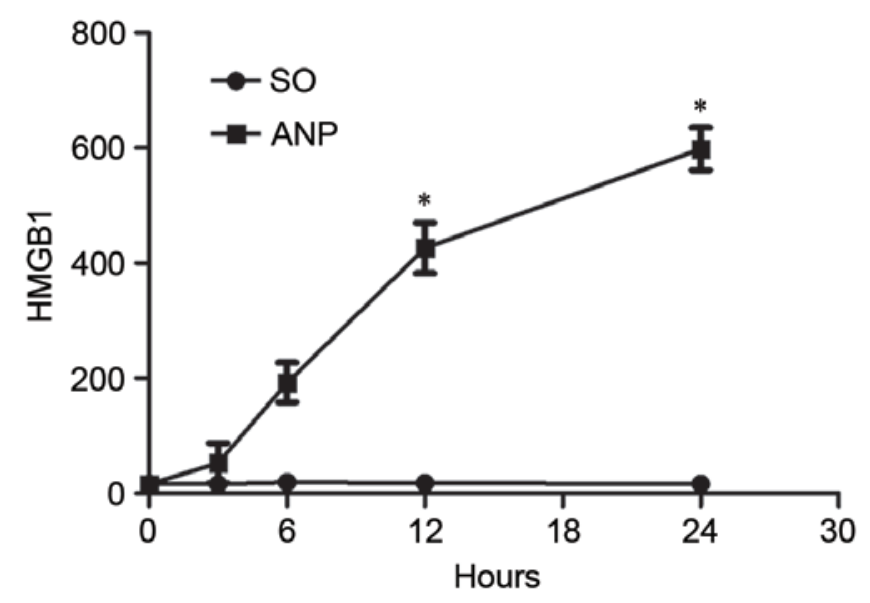

Figure 7. Serum levels of high-motility group box protein 1 (HMGB1) following generation of the acute necrotizing pancreatitis (ANP) rat model. ${ }^{\mathrm{P}} \mathrm{P}<0.05$ vs. the preceding time point. $\mathrm{SO}$, sham operation, control.

the presence of HMGB1 in the serum at various time points after ANP modeling. As presented in Fig. 7, compared with the control group, HMGB1 levels in the serum began to increase at $3 \mathrm{~h}$, and were highest at $24 \mathrm{~h}$ after modeling.

\section{Discussion}

In eukaryotes, autophagy is involved in cell physiological and pathological processes. Autophagy has a dual role, and can either protect cells against damage, or promote 
pathological processes associated with changes to the cell environment (24-28). In AP, autophagy is involved in all pathological processes; it protects the pancreas in the early stages, but promotes disease progression in the late stages (10). HMBG1 is involved in ANP-associated autophagy $(18,23,29)$; however, the exact involvement of HMGB1 in ANP remains unknown.

The aim of the present study was to determine the expression pattern of HMGB1 in ANP, and to investigate its association with autophagy. The results of the present study demonstrated that autophagy was detected $3 \mathrm{~h}$ after generation of an ANP model; however, HMGB1 expression remained unaltered during the early stage (0-6 h). HMGB1 was significantly increased at $12 \mathrm{~h}$, and was shown to be still rising at $24 \mathrm{~h}$. Notably, HMGB1 expression was significantly increased in the nuclei, rather than in the cytoplasm, at 3-6 h. In addition, in the serum, HMGB1 levels began to increase at $3 \mathrm{~h}$, and reached the highest levels at $24 \mathrm{~h}$ in the ANP group.

In the present study, a rat model of ANP was successfully established by retrogradely injecting sodium taurocholate into the biliopancreatic duct. Beclin 1, which is a critical factor in autophagy, continuously increased with the development of ANP. Furthermore, HMGB1 expression in the pancreatic tissue was not significantly altered 3 and $6 \mathrm{~h}$ after modeling, but was significantly increased at 12 and $24 \mathrm{~h}$. A previous study demonstrated time differences in the expression of early inflammatory factors, including HMGB1, TNF- $\alpha$, IL-1 and IL-6 in pancreatic tissue (29). HMGB1 may act as a key signaling molecule in activating or promoting autophagy when early inflammatory factors begin to decrease; therefore, the results of the present study lay a theoretical foundation to further explore the role of HMGB1 as a key factor in the development of AP. The results of the present study are supported by the results of a previous study, which detected increased serum and pancreatic levels of HMGB1 in humans with pancreatitis and animal models of pancreatitis (30).

Activation of trypsinogen particles and nuclear factor (NF) $-\kappa \mathrm{B}$ by autophagy is the initiating event of pancreatitis development, and has been recognized as the main pathological mechanism underlying the occurrence and development of AP (9). It has previously been demonstrated that early inflammatory factors, such as $\mathrm{NF}-\kappa \mathrm{B}$, are downregulated $\sim 12 \mathrm{~h}$ after the onset of AP (18); however, AP-induced inflammation continues, and other inflammatory cytokines act to increase inflammation. In autophagy, factors such as vacuole membrane protein 1, microtubule-associated protein light chain 3 II and Beclin 1 are involved in the non-caspase-dependent signaling pathway and have an important role in autophagy (31). However, the exact role of HMGB1 in ANP-associated autophagy is ill known. In cell nuclei, HMGB1 has a role in the transcription of numerous genes that are crucial to the autophagy process (11-14). Indeed, the present study detected increased nuclear localization of HMGB1 post-ANP induction, which may be associated with the increased autophagy features observed using TEM; these results are supported by a previous study (20). In addition, in AP, inhibition of Beclin 1 activity can inhibit autophagy and significantly reduce tissue damage (32). In the cytoplasm, HMBG1 binds to Beclin 1, sustaining the Beclin 1-Ptdlns3KC3 complex during the activation of autophagy (15).

Inhibiting HMGB1 action has been shown to suppress the development of pancreatitis (29). In addition, vitamin K3 is able to inhibit cerulein-induced AP via the inhibition of autophagy, and may reduce tissue damage (33). Therefore, inhibiting autophagy is possible to prevent the development of AP, whereas inducing autophagy may aggravate the condition. However, more studies are required to determine if Beclin 1 or HMGB1 could be considered as possible therapeutic targets in ANP.

The present study is not without its limitations. Firstly, it was performed in animals, and the exact involvement of HMGB1 in ANP may be subtly different in humans. In addition, the present study very superficially explored the involvement of HMGB1 in the mechanisms underlying ANP. Further studies are required to explore these mechanisms in detail. For example, Toll-like receptors and receptor for advanced glycation end products have been reported to be activated by HMGB1 and mediate the extracellular effects of HMGB1 $(34,35)$.

In conclusion, in the ANP model generated in the present study, HMGB1 was initially increased in the nuclei, which may result in the initiation of autophagy. Subsequently, it was translocated into the cytoplasm, where it may interact with Beclin 1 to enhance autophagy, and HMGB1 was released into the blood, leading to deterioration of ANP.

\section{Acknowledgements}

The present study was supported by the National Natural Science Foundation of China (grant no. 81270545), the Science and Technology Department of Hunan Province Foundation of China (grant no. 2013FJ6021), and by the Fundamental Research Funds for the Central Universities of Central South University (grant no. 2015zzts124).

\section{References}

1. Frossard JL, Steer ML and Pastor CM: Acute pancreatitis. Lancet 371: 143-152, 2008.

2. Banks PA, Bollen TL, Dervenis C, Gooszen HG, Johnson CD, Sarr MG, Tsiotos GG and Vege SS; Acute Pancreatitis Classification Working Group: Classification of acute pancreatitis-2012: Revision of the atlanta classification and definitions by international consensus. Gut 62: 102-111, 2013.

3. O'Farrell A, Allwright S, Toomey D, Bedford D and Conlon K: Hospital admission for acute pancreatitis in the Irish population, 1997 2004: Could the increase be due to an increase in alcohol-related pancreatitis? J Public Health (Oxf) 29: 398-404, 2007.

4. Fagenholz PJ, Fernandez-del Castillo C, Harris NS, Pelletier AJ and Camargo CA Jr: National study of united states emergency department visits for acute pancreatitis, 1993-2003. BMC Emerg Med 7: 1, 2007.

5. Tolstrup JS, Kristiansen L, Becker U and Grønbaek M: Smoking and risk of acute and chronic pancreatitis among women and men: A population-based cohort study. Arch Intern Med 169: 603-609, 2009

6. American Gastroenterological Association (AGA) Institute on 'Management of Acute Pancreatits' Clinical Practice and Economics Committee; AGA Institute Governing Board: AGA Institute: Medical position statement on acute pancreatitis. Gastroenterology 132: 2019-2021, 2007.

7. Helin H, Mero M, Markkula $\mathrm{H}$ and Helin M: Pancreatic acinar ultrastructure in human acute pancreatitis. Virchows Arch A Pathol Anat Histol 387: 259-270, 1980. 
8. Watanabe O,BaccinoFM,Steer MLand Meldolesi J: Supramaximal caerulein stimulation and ultrastructure of rat pancreatic acinar cell: Early morphological changes during development of experimental pancreatitis. Am J Physiol 246: G457-G467, 1984.

9. Sah RP and Saluja A: Molecular mechanisms of pancreatic injury. Curr Opin Gastroenterol 27: 444-451, 2011.

10. Grasso D, Ropolo A, Lo Re A, Boggio V, Molejon MI, Iovanna JL, Gonzalez CD, Urrutia R and Vaccaro MI: Zymophagy, a novel selective autophagy pathway mediated by VMP1-USP9x-p62, prevents pancreatic cell death. J Biol Chem 286: 8308-8324, 2011.

11. Tang D, Kang R, Cheh CW, Livesey KM, Liang X, Schapiro NE, Benschop R, Sparvero LJ, Amoscato AA, Tracey KJ, et al: HMGB1 release and redox regulates autophagy and apoptosis in cancer cells. Oncogene 29: 5299-5310, 2010.

12. Tang D, Kang R, Livesey KM, Cheh CW, Farkas A, Loughran P, Hoppe G, Bianchi ME, Tracey KJ, et al: Endogenous HMGB1 regulates autophagy. J Cell Biol 190: 881-892, 2010.

13. Tang D, Kang R, Livesey KM, Kroemer G, Billiar TR, Van Houten B, Zeh HJ III and Lotze MT: High-mobility group box 1 is essential for mitochondrial quality control. Cell Metab 13: 701-711, 2011.

14. Tang D, Kang R, Livesey KM, Zeh HJ III and Lotze MT: High mobility group box 1 (HMGB1) activates an autophagic response to oxidative stress. Antioxid Redox Signal 15: 2185-2195, 2011.

15. Kang R, Zeh HJ, Lotze MT and Tang D: The Beclin 1 network regulates autophagy and apoptosis. Cell Death Differ 18: 571-580, 2011.

16. Kang R, Lotze MT, Zeh HJ, Billiar TR and Tang D: Cell death and DAMPs in acute pancreatitis. Mol Med 20: 466-477, 2014.

17. Livesey KM, Kang R, Vernon P, Buchser W, Loughran P, Watkins SC, Zhang L, Manfredi JJ, Zeh HJ III, Li L, et al: p53/HMGB1 complexes regulate autophagy and apoptosis. Cancer Res 72: 1996-2005, 2012.

18. Zhang ZW, Zhang QY, Zhou MT, Liu NX, Chen TK, Zhu YF and Wu L: Antioxidant inhibits HMGB1 expression and reduces pancreas injury in rats with severe acute pancreatitis. Dig Dis Sci 55: 2529-2536, 2010.

19. Aho HJ, Koskensalo SM and Nevalainen TJ: Experimental pancreatitis in the rat. sodium taurocholate-induced acute haemorrhagic pancreatitis. Scand J Gastroenterol 15: 411-416, 1980.

20. Livak KJ and Schmittgen TD: Analysis of relative gene expression data using real-time quantitative PCR and the 2(-Delta Delta C(T)) method. Methods 25: 402-408, 2001.
21. Sailai Y, Yu X, Baiheti P, Tang H, Li Y and Xu M: Influence of nuclear factor- $\kappa \mathrm{B}$ activation on inflammatory mediators of alveolar macrophages in rats with acute necrotizing pancreatitis. Investigative Med 58: 38-42, 2010.

22. Skinner M: Autophagy: In the hands of HMGB1. Nat Rev Mol Cell Biol 11: 756-757, 2010.

23. Scaffidi P, Misteli T and Bianchi ME: Release of chromatin protein HMGB1 by necrotic cells triggers inflammation. Nature 418: 191-195, 2002.

24. Ogier-Denis E and Codogno P: Autophagy: A barrier or an adaptive response to cancer. Biochim Biophys Acta 1603: 113-128, 2003.

25. Klionsky DJ: Autophagy. Curr Biol 15: R282-R283, 2005.

26. Shintani T and Klionsky DJ: Autophagy in health and disease: A double-edged sword. Science 306: 990-995, 2004.

27. Marino G and Lopez-Otin C: Autophagy: Molecular mechanisms, physiological functions and relevance in human pathology. Cell Mol Life Sci 61: 1439-1454, 2004.

28. Eskelinen EL: Maturation of autophagic vacuoles in mammalian cells. Autophagy 1: 1-10, 2005.

29. Yasuda T, Ueda T, Shinzeki M, Sawa H, Nakajima T, Takeyama Y and Kuroda Y: Increase of high-mobility group box chromosomal protein 1 in blood and injured organs in experimental severe acute pancreatitis. Pancreas 34: 487-488, 2007.

30. Shen $X$ and Li WQ: High-mobility group box 1 protein and its role in severe acute pancreatitis. World J Gastroenterol 21: 1424-1435, 2015.

31. Pyo JO, Nah J and Jung YK: Molecules and their functions in autophagy. Exp Mol Med 44: 73-80, 2012.

32. Yang S, Bing M, Chen F, Sun Y, Chen H and Chen W: Autophagy regulation by the nuclear factor $\kappa \mathrm{B}$ signal axis in acute pancreatitis. Pancreas 41: 367-373, 2012.

33. Chinzei R, Masuda A, Nishiumi S, Nishida M, Onoyama M, Sanuki T, Fujita T, Moritoh S, Itoh T, Kutsumi H, et al: Vitamin K3 attenuates cerulein-induced acute pancreatitis through inhibition of the autophagic pathway. Pancreas 40: 84-94, 2011.

34. Asavarut P, Zhao H, Gu J and Ma D: The role of HMGB1 in inflammation-mediated organ injury. Acta Anaesthesiol Taiwan 51: 28-33, 2013.

35. Schmidt AM, Hofmann M, Taguchi A, Yan SD and Stern DM: RAGE: A multiligand receptor contributing to the cellular response in diabetic vasculopathy and inflammation. Semin Thromb Hemost 26: 485-493, 2000. 